\title{
"PORQUE SÓLO LA ILUSTRACIÓN PUEDE DESTERRAR DE ESOS PUEBLOS LOS VICIOS Y LA INMORALIDAD QUE LOS DOMINAN" * INDÍGENAS Y EDUCACIÓN EN OAXACA (1823-1867)
}

\author{
Francisco José Ruiz Cervantes \\ Universidad Autónoma Benito Juárez de Oaxaca \\ Daniela Traffano \\ Centro de Investigaciones y Estudios Superiores \\ en Antropología Social, Unidad Istmo
}

\begin{abstract}
Resumo
O presente artigo estuda a situação da educação no estado de Oaxaca entre a Independência e a República Restaurada. Em sua maioria indígena, a população da entidade era considerada pela elite política e intelectual do século XIX o obstáculo a ser superado para alcançar-se a civilização e a estabilidade. Logo se difundiu a teoria de que o Estado tinha que se encarregar de solucionar o problema e que a melhor maneira seria por meio de uma educação obrigatória, gratuita e laica. O texto que segue apresenta as idéias liberais sobre "o problema indígena" e as diretrizes para sua "solução" através da análise da legislação que auspiciou e regulamentou o sistema educativo tanto no aspecto administrativo como para a formação docente.
\end{abstract}

\section{Pallavras-Chave}

Educação • Indígenas • Oaxaca • Século XIX • Liberais

\section{Abstract}

The present article studies the situation of education in the state of Oaxaca between the period of Independence and the Restored Republic. Mostly indigenous, the population was considered the impeding obstacle in order to achieve civilization and stability, according to the political and intellectual $19^{\text {th }}$ century elite. Soon after, the idea spread that the State was responsible for solving this problem; and the most effective solution would be through mandatory, free, and lay education. The fallowing text presents liberal ideas on "the indigenous problem" and the dealings of its "solution" through the analysis of the legislation that made possible and designed the educational system, both at the administrative level and at the teaching professional development level.

\section{Keywords}

Education $\bullet$ Indigenous $\bullet$ Oaxaca $\bullet 19^{\text {th }}$ Century $\bullet$ Liberals

"Memoria administrativa, 1850: 10. 


\section{Introducción}

Al periodo histórico que se inició con la consumación de la independencia de México en 1821 y concluyó casi medio siglo después con el triunfo de la república en 1867 se le conoció como de la anarquía. Tal caracterización se nutrió del continuo estancamiento económico, permanente bancarrota de las finanzas públicas, inestabilidad política crónica, conflictos con el exterior como incursiones militares extranjeras y la pérdida de más de la mitad del territorio, resultado de la guerra con los Estados Unidos ${ }^{1}$.

En el recién constituido país, la minoría criolla, beneficiaria de la gesta independentista, aliada con la jerarquía de la iglesia católica y la oficialidad militar, ambas instituciones provenientes del periodo colonial, se dieron a la tarea de formular escenarios políticos que privilegiaran el mantenimiento de la tradición, por encima de la urgencia de cambios para la inmensa mayoría de la población formada por indígenas, castas y mestizos.

Las elites se enfrascaron en constantes conflictos por definir lo que consideraban el mejor rumbo para la nueva nación. Así, del régimen monarquista de Agustín de Iturbide se pasó a la primera república federal y de ahí a la similar de corte centralista y nuevamente el régimen federal se impuso cuando arrancaba la guerra con Norteamérica, lo que dicho de paso perjudicó la causa de la defensa nacional ${ }^{2}$.

La derrota ante el invasor yanqui y la pérdida del territorio en 1847 no fue suficiente para apaciguar los ánimos y, tras un breve momento de calma, volvió el caudillo insustituible Antonio López de Santa Anna, ahora impulsado por los conservadores. De nueva cuenta, los liberales se organizaron y validos del apoyo de Juan Álvarez, el viejo caudillo del sur, lucharon hasta deponer a su "Alteza Serenísima"3.

El triunfo del partido liberal y el llamamiento a un nuevo congreso constituyente en 1856 propiciaron la redacción de una carta magna que por primera

\footnotetext{
${ }^{1}$ No deja de ser significativo que el título del capítulo escrito por la Dra. Josefina Zoraida Vázquez que agrupa lo ocurrido en México entre 1821 y 1854, en la síntesis historiográfica más ambiciosa escrita a fines del siglo veinte, sea "Los primeros tropiezos". Historia general de México, 2000, México: El Colegio de México, pp. 525-582.

${ }^{2}$ Historia general de México, 2000, México: El Colegio de México, pp. 525-582.

${ }^{3}$ Historia general de México, op.cit., pp. 583-592.
} 
vez reservó un espacio para instaurar los derechos individuales a los ciudadanos. Otra vez, la iglesia católica y el llamado partido conservador se unieron y la guerra civil se enseñoreó en el país por tres años más, contando con la intervención de países europeos y naturalmente de Norteamérica ${ }^{4}$.

El triunfo de los liberales en 1861 no pacificó de inmediato a la república, el bandolerismo era una realidad omnipresente en la mayoría de los viejos caminos del país y los delincuentes hacían de las suyas a la luz del día. No fue casual que la mejor novela de costumbres de la época se llame Los bandidos de Río Frío ${ }^{5}$.

Para colmo, la suspensión temporal del pago de la deuda externa que la administración juarista dispuso para mejorar el estado de las finanzas públicas trajo como consecuencia la coalición de las potencias acreedoras. La llegada a las costas mexicanas de las naves de guerra españolas, inglesas y francesas abrió el camino al enfrentamiento bélico. Una vez más, los mexicanos, "los últimos entre los hombres" según la expresión de la época, se enfrentaron al ejército francés vencedor de múltiples batallas en Europa y Asia ${ }^{6}$.

La ocupación francesa apuntaló la instauración del efímero Imperio de Maximiliano de Habsburgo y de nuevo la guerra dividió a los mexicanos. Sin embargo, un par de acontecimientos ocurridos fuera de las fronteras nacionales, el triunfo del Norte sobre el Sur en la guerra civil estadounidense y la agudización de las contradicciones entre Francia y Prusia, favorecieron la causa republicana y las fuerzas juaristas acumularon triunfos decisivos, mientras el balbuceante imperio del príncipe austriaco hacía agua hasta hundirse con su representante, fusilado en tierra mexicana ${ }^{7}$.

Concluida esa coyuntura, la elite política afiliada al grupo liberal encabezada por el primer presidente de origen indígena se encaminó por la ruta de la "Libertad, el Orden y el Progreso". Benito Juárez se interesó notablemente en el dis-

\footnotetext{
${ }^{4}$ Historia general de México, op.cit., pp. 592-603.

${ }^{5}$ El autor fue Manuel Payno, escritor exponente del romanticismo mexicano decimonónico; Otro joven literato de sangre indígena Ignacio Manuel Altamirano escribió Los plateados, título que hacía referencia a las costumbres de los bandoleros de adornarse con prendas de plata, los pantalones, la chaqueta y el sombrero.

${ }^{6}$ HAMNETT, Brayan. Historia de México. Madrid: Cambridge University Press, 2001, pp. 186-187.
}

${ }^{7}$ HAMNETT, Brayan. Op. Cit., pp. 187-189, 192-193. 
curso pronunciado por el Dr. Gabino Barreda al interpretar la historia de México de acuerdo a los tres estadios del espíritu descritos por el francés Augusto Comte ${ }^{8}$.

Poco tiempo después, el propio mandatario encargó a una comisión dirigida por Barreda trabajar para organizar la instrucción pública; el resultado fue la llamada Ley Orgánica de Instrucción Pública, de diciembre de $1867^{9}$.

En 1867, la generación liberal, con Benito Juárez al frente, tenía ante sí los problemas más urgentes del país pero a diferencia de otros momentos, el partido liberal no tenía oponente histórico. La Iglesia católica fue severamente afectada en sus propiedades por la constitución del 57 y las Leyes de Reforma y la corporación militar desapareció de los campos de batalla. Los liberales tendrían la tarea de construir con bases firmes el moderno estado mexicano ${ }^{10}$.

\section{II}

Según cálculos de la época, la población de la Nueva España alcanzó en 1810 la cantidad de seis millones de personas, de las cuales, el 60 por ciento podía considerarse indígena; el 21 por ciento pertenecía a las castas y el 18 por ciento a los españoles (nacidos en la Metrópoli o en la colonia) ${ }^{11}$. Luego de una década de guerra de independencia la cifra calculada seguía siendo del orden de los seis millones y fracción, a lo largo del siglo XIX creció a pesar de las disputas intestinas y la mortandad ocasionada por epidemias como el cólera que enviaba periódicamente a buen número de personas a los cementerios.

Al surgir México a la vida institucional se dejaron de considerar las afiliaciones raciales y genéricamente todos se convirtieron en mexicanos; no obstante,

\footnotetext{
${ }^{8}$ El médico Barreda siguió el curso impartido por Comte sobre historia general de la humanidad. GONZÁLEZ RAMÍREZ, Moisés. Sociología e historia en México. México: El Colegio de México, Jornadas 67, 1985, p. 3; VILLEGAS, Abelardo. Positivismo y porfirismo. México: SEP-Setentas, 1972; RAAT, William D. El positivismo durante el porfiriato. México: SEPSetentas, 1975, p. 15.

${ }^{9}$ VÁZQUEZZORAIDA DE KNAUTH, Josefina. "La república restaurada y la educación. Un intento de victoria definitiva" En: Varias, La educación en la historia de México. Lectura de Historia Mexicana. México: El Colegio de México, 1992, pp. 93-103.

${ }^{10}$ BAZANT, Jean. Breve historia de México. De Hidalgo a Cárdenas (1805-1940). México: Premia Editora, 1986, p. 86,

${ }^{11}$ de GORTARI RABIELA, Hira. “Territorio y población de la Nueva España de fines del siglo XVII al México independiente” En: Varios, El poblamiento de México. Una visión histórico-demográfica. México: SG-CONAPO, t. III (México en el siglo XIX), 1993, p. 45.
} 
estas nuevas costumbres y denominaciones, en entidades del sur del país el porcentaje mayoritario era indígena. Así, se calcula que en Oaxaca, la proporción de hombres y mujeres pertenecientes a los grupos originarios era cercana al 90\%, la mayoría vivía en pueblos, en tanto, el restante diez por ciento se lo repartían castas y españoles residentes en el único asentamiento urbano de la zona, la ciudad de Oaxaca ${ }^{12}$.

De lo reportado por la investigadora Leticia Reina se concluye que no obstante la merma de las actividades económicas que dieron renombre a la intendencia novohispana, así como la presencia de epidemias de cólera hacia mediados de ese siglo XIX, la composición étnica se mantuvo constante respecto a los indígenas pero no así en los descendientes de los españoles cuya aportación se redujo a un punto porcentual ${ }^{13}$.

El cuadro quedaría incompleto si no mencionamos que en un panorama de estancamiento económico, el predominante en Oaxaca hasta mediados del siglo XIX, las sequías asolaron frecuentemente al agro, empobreciendo aún más a la mayoría de la población, sin contar ya con el auxilio que para los campesinos indígenas significó, en la centuria anterior, la explotación de la llamada grana cochinilla, colorante de origen animal de amplia aceptación en la industria textil europea, y cuya venta, a pesar de la explotación de los intermediarios españoles, les proporcionó recursos monetarios ${ }^{14}$.

Este panorama adverso para los pueblos indígenas se ensombreció más por las cada vez más frecuentes hostilidades contra sus propiedades comunales desde los tiempos coloniales. Bajo un patrón que se observa en el México decimonónico, con frecuencia las comunidades oaxaqueñas tomaron el camino de la rebelión.

Desde el siglo XVIII, por disposición de la Corona española, los pueblos indígenas y sus autoridades se abocaron a la apertura de escuelas elementales ${ }^{15}$.

\footnotetext{
${ }^{12}$ de GORTARI RABIELA, Hira. "Territorio y población de la Nueva España de fines del siglo XVII al México independiente" En: Varios, El poblamiento de México. Una visión históricodemográfica. México: SG-CONAPO, t. III (México en el siglo XIX), 1993, p. 49.

${ }^{13}$ REINA, Leticia. Caminos de luz y sombra. Historia indígena de Oaxaca en el siglo XIX. México: CIESAS-CDI, 2004, pp. 102-103.

${ }^{14}$ ROMERO FRIZZI, Maria de los Ángeles (coorda.). Lecturas históricas del estado de Oaxaca. Oaxaca: INAH, Gobierno del Estado, vol. III, 1990, pp. 36-37; SÁNCHEZ SILVA, Carlos. Indios, comerciantes y burocracia en la Oaxaca poscolonial, 1786-1860, Oaxaca, IOC-FOESCA-UABJO, 1998, pp. 96-110.

${ }^{15}$ TANCK DE ESTRADA, Dorothy. Pueblos de indios y educación en el México colonial. México: Colmex, 2000.
} 
Esa medida se reforzó en el articulado de la Constitución de Cádiz, aprobada en 1812, que otorgaba facultades a los ayuntamientos para hacerse cargo de la instrucción pública.

Una vez concluida la Independencia, sin importar banderías y credos políticos, los principales intelectuales del momento se pronunciaron por la conveniencia de abrir centros escolares en el nuevo país. La instrucción pública se convirtió en una especie de "panacea, capaz de desalentar a los indígenas a rebelarse"

Esa convicción se volcó al terreno legal y luego de la expedición de la primera Constitución política de México, en el año de 1824, la mayoría de las entidades que integraban la federación dieron a conocer leyes de instrucción pública en donde se detallaban las facultades de los gobiernos estatales, los ayuntamientos y los particulares para la apertura y sostenimiento de escuelas, y también para la formación de quienes deberían atenderlas; proceso que detallaremos más adelante para el caso oaxaqueño.

\section{Los indígenas en el pensamiento nacional}

Para acercarnos a este tema es necesario retomar la preocupación con la que tanto federalistas y centralistas, liberales y conservadores, desde la Independencia, habían mirado a la población indígena, que deseaban integrar a la nación ${ }^{17}$. Naturalmente esos dos grupos políticos tenían una diferente visión de la situación y propusieron distintas soluciones a los problemas del país. Lucas Alamán por ejemplo, máximo representante del grupo conservador, sostenía que México era producto de la Colonia y que su cultura, educación y religión debían de conservarse por estar basados en los principios de la tradición española que él consideraba de mayor solidez política y social. Alamán creía

\footnotetext{
${ }^{16}$ STAPLES, Anne. En: Varias, La educación en la historia de México. Lectura de Historia Mexicana. México: El Colegio de México, 1992, p. 90

${ }^{17}$ Muchos intelectuales decimonónicos se han ocupado del tema analizándolo desde distintos puntos de vista y presentando diversas explicaciones y propuestas. Entre ellos recurren José Maria Luis Mora, Lucas Alamán, Lorenzo de Zavala y Mariano Otero en la primera mitad del siglo XIX. Francisco Pimentel, Antonio García Cubas, Guillermo Prieto, Ignacio Manuel Altamirano, Ignacio Ramírez, Gabino Barreda, José Díaz Covarrubias, José Maria Castillo Velasco son unas de las primeras voces de la segunda mitad del siglo a las que se unieron, hasta principio del siglo XX, las de Francisco Cosmes, Justo Sierra, Joaquín Baranda, Francisco Bulnes o Genaro García entre otros.
} 
que la situación social no debía cambiar en el México independiente, ya que los indígenas no estaban preparados para vivir en condiciones de igualdad con el resto de la población; era necesario mantenerlos en el mismo estado de protección que habían tenido durante la Colonia ${ }^{18}$.

Al contrario, el liberal José Maria Luis Mora condenó tanto el pasado prehispánico como el colonial. Para él, el indio era una persona atrasada debido al tutelaje al que estuvo sometido en la Colonia y como Lorenzo de Zavala, otro pensador federalista, consideró fundamental la idea de la propiedad privada que permitiría el desarrollo del país así como la incorporación de los indígenas a una sociedad con unas mismas leyes y derechos civiles y políticos ${ }^{19}$.

En efecto, los primeros pasos hacia la integración habían sido la igualdad jurídica entre todos los habitantes del país y la intervención sobre la propiedad comunal para que el indígena se convirtiera en propietario particular y así "saliera de su estado de inmovilidad social y económica". Alineado con esta idea, Guillermo Prieto se había declarado contrario a la propiedad comunal y había criticado la nefasta influencia del clero sobre el indígena. Según él, era necesario separarlo de la Iglesia, educarlo y fraccionar sus tierras en propiedad privada ${ }^{20}$. De la misma manera, durante el Imperio de Maximiliano, Francisco Pimentel señalaba como causas de la degradación del indio su dependencia de la propiedad comunal y su idolatría. Como remedios para resolver la situación de la "raza indígena" proponía una religión católica ilustrada, la eliminación del sistema de comunidad y del aislamiento en el que vivían, así como la supresión de sus lenguas y costumbres. Para eso era indispensable añadir una intervención externa que apuntara a una sociedad nacional homogénea y a una población mestiza ${ }^{21}$. El mismo Pimentel sugería la mezcla de la raza indígena con la blanca y elogiaba la fuerza, el valor, la generosidad y la lealtad del mestizo.

Para lograr tal fin, políticos e intelectuales plantearon la necesidad de incrementar un programa concertado de colonización europea masiva pero selectiva.

${ }^{18}$ CHAVEZ CHAVEZ, Jorge. "El pensamiento indigenista decimonónico" En: Carlos García Mora (coord.) La antropología en Mexico. México: INAH, vol. 3, 1987.

${ }^{19}$ MORA, J.M. Luis. Obras sueltas. México, 1963.

${ }^{20}$ CHAVEZ CHAVEZ, Jorge. "El pensamiento indigenista decimonónico" En: Carlos García Mora (coord.) La antropología en Mexico. México: INAH, vol. 3, 1987.

${ }^{21}$ PIMENTEL, Francisco. Dos obras de Francisco Pimentel. Mexico: CONACULTA, 1995. 
Los inmigrantes, ocupando y trabajando las tierras baldías, revitalizarían la economía del país y acabarían gradualmente con la raza indígena que en el término de un siglo, cesaría de ser tal. Entre los exponentes de esta posición se encontraban García Cubas, Bulnes y Riva Palacios ${ }^{22}$; éste último calculaba que en un siglo o dos México podía llegar a purgarse de su fondo biológico indio y "blanquearse" completamente. Finalmente, tanto los liberales como los conservadores compartieron la idea de que para civilizar al indio era necesario educarlo y consideraron la educación como "una especie de regeneradora de razas" capaz de dar comienzo al proceso de construcción de la nación ${ }^{23}$.

\section{Los indígenas en Oaxaca}

En Oaxaca, la elite, que no pudo ignorar la preponderante presencia indígena en la entidad, se pronunció a propósito explicando su posición en los discursos oficiales y la prensa. Es necesario señalar que las consideraciones relativas a la población indígena variaron con el tiempo y según la específica posición de cada político o intelectual. Si, en general, durante el periodo estudiado los indios fueron considerados "un problema," la relevancia del mismo no fue igual en las primeras décadas de independencia y durante los gobiernos liberales o la intervención, dependiendo de la coyuntura específica.

Las descripciones oficiales de la población originaria del México postcolonial se asociaron con las palabras ignorancia, incivilización, inmoralidad y vicios que enmarcaron la imagen de un sujeto - el indio - bárbaro, descalzo y desnudo, arraigado a sus costumbres, desgraciado, supersticioso, oprimido y

\footnotetext{
${ }^{22}$ CHAVEZ CHAVEZ, Jorge. Op.cit.

${ }^{23}$ ESCOBAR OHMSTEDE, Antonio; ROJAS RABIELA, Teresa (coords.). La presencia del indígena en la prensa capitalina del siglo XIX. México: CIESAS-INI, cuatro volúmenes, 1992, p. 15; STABB, Martin. "Indigenism and Racism in Mexican Thought: 1857-1911" En: Journal of Inter-American Studies, vol. 1, n. 4, 1959; POWELL, T.G. "Mexican Intellectuals and the Indian Question" En: The Hispanic American Historical Review, vol. XLVIII, n. 1, 1968; RAAT, William D. "Los intelectuales, el positivismo y la cuestión indígena” En: Historia Mexicana, vol. XX, n.79, 1971; ESCOBAR OHMSTEDE, Antonio. "Politica indigenista en el México del siglo XIX (1800-1857)” En: Papeles de la Casa Chata. México: SEP, n. 4, 1988; FAVRE, Henri. "Raza y nación en México, de la Independencia a la Revolución” En: Cuadernos Americanos, n.45, 1994; FERRER MUÑOZ, Manuel (coord.). Los pueblos indios y el parteaguas de la Independencia de México. México: UNAM, 1999; FERRER MUÑOZ, Manuel y BONO LÓPEZ, Maria. Pueblos indígenas y estado nacional en México en el siglo XIX. México: UNAM, 1998.
} 
esclavo. En un folleto de 1823 titulado Invitación que hace un oaxaqueño a su suelo patrio, el autor sostiene que los indígenas, "ciegos observadores de las costumbres de sus mayores", han vivido siempre "el abandono y desprecio trabajando en muchas partes sólo el tiempo preciso para coger su maíz y el resto del año entregándose al ocio". Sin embargo, porque lo aprendieron de sus padres tienen dineros enterrados que, solo adquiriendo "ideas de mejor gusto y confiando en el gobierno", sacarán a beneficio del erario publico y el Arca provincial. El autor proponía un plan de intervención que buscaba cambiar esa situación de ignorancia; un plan que implicaba la instrucción generalizada con maestros sostenidos por el gobierno y destinada a los indios que, reunidos en la ciudad, se instruirían y educarían. Éstos, escribía el anónimo redactor “cuando vuelvan a sus pueblos", podrán comunicar "a los vecinos, con el roce y trato, la instrucción que han adquirido, resultando de aquí el bien de todos". Nada es más justo para el autor que:

\begin{abstract}
"estos ciudadanos gocen en tiempo de libertad y seguridad, de aquello que ocultaron en los calamitosos días de opresión, violencia y arbitrariedad. Se civilizarán así cuanto antes y los hijos de éstos, ya ilustrados, no sufriendo un nuevo yugo sobre los hombros, serán el apoyo y esperanza del estado". ${ }^{24}$
\end{abstract}

Para los gobernadores que administraron Oaxaca en los años sucesivos a la consolidación de la Independencia, la población indigena siguió caracterizándose por vivir en un estado de barbarie, por ser ignorante, inmoral e incivil y encontrarse sumergida en "un abismo de tinieblas" 25 . El tenor de las observaciones no varió durante la gubernatura de Juárez. Si bien él se caracterizó por ser un gobernador preocupado por la situación económica y educativa de la población del estado, los pueblos indios siguieron adjetivados como ignorantes ${ }^{26} \mathrm{y}$, por viciosos e inmorales, tachados de provocadores de desordenes $\mathrm{y}$

\footnotetext{
${ }^{24}$ ANÓNIMO, "Invitación que hace un oaxaqueño a su suelo patrio" (1823), En: SÁNCHEZ SILVA, Carlos y RUIZ CERVANTES, Francisco José. Pensamiento político y social oaxaqueño. Oaxaca: IEEPO, 2000, pp. 23-24.

${ }^{25}$ Memorias administrativas 1827, 1831, 1832, 1835.

${ }^{26}$ Memoria administrativa 1848, 1852.
} 
violencia $^{27}$. En 1856, el oaxaqueño Castillo Velasco, hablaba al Congreso Constituyente de esa "raza desgraciada de hombres que llamamos indígenas, [...] humillados con su pobreza infinita, [...] más infelices que los eslavos, mas infelices aun que las bestias porque sienten su degradación y miseria"28. El congresista sostenía que:

"para que pudiera penetrar la luz de la civilización en esos pueblos era necesario disipar los nublados de su indigencia; para que llegaran sus moradores a adquirir la dignidad de hombres libres, fuerza era que se les proporcionasen los medios de subsistir y cuantos eran necesarios para que, palpando las ventajas de la libertad, supieran usar de ella y amarla y defenderla" 29 .

Para poder superar la miseria y la indigencia el diputado proponía autorizar una cierta autonomía financiera a los ayuntamientos y la dotación de tierras a los indígenas. Pocos años después, el triunfo del gobierno liberal encontraba eco y apoyo también en la prensa local. En Oaxaca, La Victoria, periódico del gobierno del estado, elogiaba a la clase indigena por haberse "manifestado amiga de la revolución" 30 , por haber comprendido "como por instinto que en ese movimiento que agita la muchedumbre, en esas voces misteriosas que se levantan por todas partes, se encierra el secreto de su bienestar futuro". La revolución era lo que los indios necesitaban porque sólo aquélla, en su "marcha civilizadora", podría "elevar a la clase indígena a la esfera que le corresponde como criaturas racionales" y podría emancipar "esa multitud de seres desgraciados que gimen bajo las dobles cadenas de la miseria y de la ignorancia"31.

\footnotetext{
${ }^{27}$ Memoria administrativa 1850.

${ }^{28}$ CASTILlO VELASCO, José María, "Voto particular del diputado José María Castillo Velasco presentado en el Congreso Constituyente de 1856-1857” (1856), En: SÁNCHEZ SILVA, Carlos y RUIZ CERVANTES, Francisco José. Pensamiento político y social oaxaqueño. Oaxaca: IEEPO, 1998, p. 62.

${ }^{29}$ CASTILlO VELASCO, José María, "Voto particular del diputado José María Castillo Velasco presentado en el Congreso Constituyente de 1856-1857” (1856) En: SÁNCHEZ SILVA, Carlos y RUIZ CERVANTES, Francisco José. Pensamiento político y social oaxaqueño. Oaxaca: IEEPO, 1998, p. 62.

${ }^{30}$ La Victoria, 10 de marzo de 1861.

${ }^{31}$ La Victoria, 10 de marzo de 1861.
} 
A principio de los años sesenta del siglo XIX, Oaxaca todavía no se había liberado de ese "otro" irracional, desgraciado, miserable y sumamente pobre. Ese "otro" que sólo sometido a una oportuna "elevación" dejaría libre al Estado, el camino del desarrollo hacia la modernidad.

La preocupación por el progreso era una constante en el pensamiento y el discurso de los políticos que, en buena medida, habían visto a los indígenas como el primer obstáculo a superar. En 1861, el gobernador Ramón Cajiga ilustraba con angustia al Congreso que el estado sufría una población de:

"ciudadanos que no conocen el castellano, que no tienen necesidades que satisfacer, que viven como salvajes, sin patria ni hogar, que se alimentan con frutas tomadas al caso, que desconocen la familia, que se ríen de los lazos sociales y que a veces ignoran que existe Dios".

Son éstos:

"pueblos llenos de supersticiones [que] yacen en la más completa ignorancia, [en donde] hay presidentes municipales que tienen que andar diez leguas para que el del pueblo vecino les haga conocer el contenido de las comunicaciones oficiales que se les dirigen [....] Muchos de ellos se glorían de no contar en su seno gente de razón como ellos llaman a los que hablan y comprenden el castellano, y se irritan y levantan la voz al cielo cuando el gobierno, severo eficaz y vigilante ordena el establecimiento de escuelas primarias, en donde se forme el espíritu y el corazón de nuestro ciudadanos". ${ }^{32}$

Para el mandatario, el retraso del Estado era evidente y mientras prevalecieran la miseria, la ignorancia, las largas distancias y los malos caminos, la mortalidad, la guerra civil, las diversas clases y razas, las preocupaciones, la intolerancia y la falta de inmigración "Oaxaca no progresará y [...] suspenderá la marcha que ha emprendido, retrogradando palpablemente al estado del que nuestros padres pretendieron sacarnos" ${ }^{\prime 3}$. Pocos años después, para el Imperio los indígenas seguían estando encadenados y oprimidos y en una "abyecta

\footnotetext{
${ }^{32}$ Memoria Administrativa 1861, p. 46

${ }^{33}$ Memoria Administrativa 1861, p. 46.
} 
posición" que ni siquiera la Independencia y la República habían podido modificar. Sin embargo, se esperaba que con el gobierno imperial, que apreciaba a la clase indígena en lo que valía, por ser la fuerza del Estado y de su porvenir, los indios volverían a recobrar el vigor que habían tenido en tiempo de la monarquía azteca y contribuiría al engrandecimiento del país ${ }^{34}$.

Con la restauración de la República, las opiniones sobre la población indígena no variaron sustancialmente, reafirmándose, las imágenes del indio decimonónico como el sujeto con carencias - sin educación, sin moral, sin higiene, sin cultura, sin sustentos - que solo una intervención del Estado podía llegar a cambiar y volver funcional al progreso y la modernidad ${ }^{35}$.

\section{La educación como propuesta}

Si bien la trágica realidad de los miserables indígenas prevaleció en las observaciones de la elite oaxaqueña a lo largo del siglo XIX; el imaginario en torno del indio, de su carácter, de su índole y de su pasado no siempre se caracterizó por su negatividad ni por la homogeneidad en los pareceres. Así, el oaxaqueño Castillo Velasco señalaba su aptitud para la guerra y la paz, para las artes y la ciencia, su tesón y empeño, sus instintos de severa justicia y abnegación para cumplir con la ley ${ }^{36}$. El Boletín oficial lo consideraba dócil, laborioso y afecto al suelo que lo ha visto nacer, y lo definía como el mexicano de la víspera, poseedor de todas las cualidades que habían de constituir al perfecto ciudadano $^{37}$. Finalmente, para La Victoria, el indio era reconocidamente patriota, valiente, leal, reservado, sobrio, ágil, infatigable e inteligente, a él se le debía la vida de la agricultura y el consumo de las otras industrias del país ${ }^{38}$.

\footnotetext{
${ }^{34}$ El Boletín Oficial, 26 de abril de 1866.

${ }^{35}$ Traffano, Daniela, "En torno a la cuestión indígena en Oaxaca: la prensa y el discurso de los políticos" en Sánchez Silva Carlos coord.: Historia, sociedad y literatura de Oaxaca. Nuevos enfoques. Oaxaca: UABJO, IEEPO, 2004.

${ }^{36}$ CASTILLO VELASCO, José María. "Voto particular del diputado José María Castillo Velasco presentado en el Congreso Constituyente de 1856-1857”, (1856), En: SÁNCHEZ SILVA, Carlos y RUIZ CERVANTES, Francisco José. Pensamiento político y social oaxaqueño. Oaxaca: IEEPO, 1998, p. 62.

${ }^{37}$ El Boletín Oficial, 26 de abril de 1866.

${ }^{38}$ La Victoria, 14 de febrero de 1867.
} 
Para quienes estaban dispuestos a rescatar lo bueno de la raza indígena, la gloria de su idealizado pasado prehispánico (donde "fueron ellos los nobles señores de este hermoso país") se derrumbó con la Conquista. La responsabilidad de la degradación, ignorancia y miseria de los indios recaía inevitablemente sobre los conquistadores: los soldados del rey y de dios. Estas apreciaciones y teorías sirvieron para reforzar, en la elite y la opinión pública, que solamente un poder representativo de toda la sociedad podía redimir la dramática historia de la raza indígena y salvar, elevar, emancipar, desbarbarizar, moralizar y sobre todo ilustrar e instruir esa porción de la población. Para eso, las voces se elevaron a favor del fomento de la educación, en específico, la educación escolarizada.

Los principios y las exigencias básicos que habían guiado esas voces se encontraban en los proyectos decimonónicos de desarrollo económico y social del estado y del país. La construcción de una nación activa y dinámica en su producción, comercio y consumo iba de la mano con la formación de una población que pudiera entender e interiorizar los principios de individualización de la sociedad y de participación política ciudadana. En esta perspectiva, correspondía al estado liberal el papel de "agente del cambio", fomentando y sosteniendo la creación de una nueva realidad socio-económica.

Así desde la Independencia, la opinión publica se pronunció a favor de la difusión de una educación que con el transcurrir de siglo llegó a afirmarse como publica, obligatoria, gratuita y laica. Desde 1823 el anónimo autor de la invitación al suelo patrio había propuesto un plan de educación para los indígenas dirigido y promovido por el gobierno.

Luego, en los treinta la convicción común era que "un estado libre soberano e independiente [...] necesita de ciudadanos de ilustración, conocimiento y virtudes y por consiguiente que una general instrucción forme esa porción de hombres útiles que hagan el bien de la comunidad" ${ }^{39}$. La prensa insistía en la buena educación para la felicidad de $\operatorname{los}$ pueblos $^{40}$ y que eran sumamente evidentes "las grandes ventajas, o enormes perjuicios que resultan a la sociedad de la clase de educación que se le da a los niños" ${ }^{\text {.1 }}$. Para la segunda mitad de los cincuentas, José Indelicato, director de El Constituyente, postulaba que "es

\footnotetext{
${ }^{39}$ Memoria administrativa 1831.

${ }^{40}$ El Dia, 5 de diciembre de 1837.

${ }^{41}$ El Dia, 25 de enero de 1838.
} 
preciso observar que la instrucción del pueblo no debe limitarse a lo que universalmente se cree que la complete; a saber a enseñarle a leer y escribir. Instruir al pueblo es enseñarle todo lo que puede servir a hacerle comprender su posición social; la teoría de sus derechos, la practica de sus deberes. [...] La república sin la instrucción del pueblo en todo lo que le concierne, es una estatua de oro sobre bases de greda" ${ }^{42}$. A su vez el gobernador José María Díaz Ordaz sostenía frente al Congreso:

“[...] la influencia que la ilustración ejercía en el porvenir y felicidad de los pueblos, la necesidad de proteger su desarrollo y perfección, el deber que todo gobierno tenía de fomentarla, porque regeneraba el espíritu publico, acostumbraba a la obediencia, suavizaba las costumbres e inspiraba amor al trabajo, eran verdades absolutas e impostergables". ${ }^{43}$

Del mismo tenor fue el mensaje del último gobernador liberal que antecedió al II Imperio. Firme en sus convicciones Cajiga, declaraba que el Estado le debía a "las masas educación política e instrucción primaria" porque únicamente con la difusión de la ciencia y la ilustración "todos comprenden sus deberes y los cumplen, todos conocen sus derechos y reclaman su violación, todos trabajan en provecho de la comunidad, trabajando para sí y el pueblo que antes era la rémora del progreso" 4 .

\section{Los caminos de la educación: entre formación docente y administración pública}

Bajo esos principios y lemas, relativos a la educación, que ocuparon el discurso de la elite, una vez consumada la independencia política de México en 1821, los políticos oaxaqueños le apostaron a crear escenarios donde la educación fuera una de las palancas confiables para lograr "la felicidad" de los nuevos ciudadanos. Con el lema de "más escuelas equivale a mejores ciudadanos" la preocupación educativa nacional se hizo realidad en la propuesta del sistema de

\footnotetext{
${ }^{42}$ INDELICATO, José. "De la instrucción del pueblo" En: El Constituyente, t. I, n. 10; 29 de mayo 1856, p. 2.

${ }^{43}$ Memoria administrativa, 1858, p. 29.

${ }^{44}$ Memoria administrativa 1861.
} 
enseñanza lancasteriana o "enseñanza mutua" durante el efímero Imperio de Agustín de Iturbide al fundarse la primera escuela de ese corte en $1822^{45}$.

Al establecerse la primera República, la Compañía Lancasteriana instaló en la ciudad de México un plantel denominado "La Filantropía" en donde ofrecía un curso para formar en seis meses profesores de primeras letras que siguieran el nuevo método ${ }^{46}$. Por acuerdo del gobierno oaxaqueño se envió al joven Manuel Tomás Orozco para entrenarse en la novedosa propuesta docente.

Al regreso del comisionado, luego de obtener el diploma correspondiente, el Congreso constituyente oaxaqueño emitió el 30 de diciembre de 1824 un largo decreto por el que se ordenaba el establecimiento en la ciudad capital de "una escuela normal de enseñanza mutua" en donde, bajo la dirección del propio Orozco, se formaran maestros que propagaran este método en los pueblos del estado $^{47}$. En la nueva escuela se enseñaría a leer, escribir, contar, el catecismo de la religión católica y el catecismo político, luego de su configuración. A los alumnos se les daría enseñanza gratuita y todo lo necesario para su instrucción.

En el artículo 12 del citado decreto se instituía que el gobernador del Estado invitaría, mediante el juez de primera instancia, a ciudadanos de todos los partidos para que remitieran a todos los niños deseosos de instruirse en Oaxaca, en el entendido de que sólo costearían sus alimentos y habitación. Igualmente se pediría a los jueces enviaran a un par de jóvenes mayores de 20 años, alfabetos, con deseos de enseñar y buena conducta para que entraran al curso normal, obtenida su aprobación y diploma de profesores, regresarían a sus lugares de origen para establecer escuelas de enseñanza mutua. La alimentación y el hospedaje se les daría gratuitamente por filántropos benevolentes ${ }^{48}$.

\footnotetext{
${ }^{45}$ STAPLES, Anne, "Panorama educativo al comienzo de la vida independiente" En: Ensayos sobre historia de la educación en México. México: El Colegio de México, 1981, p. 115; TANCK ESTRADA, Dorothy. "Las escuelas lancasterianas en la ciudad de Méxio: 1822-1841" En: Historia Mexicana. México: El Colegio de México, n. 88, abril-junio, 1973, p. 494.

${ }^{46}$ MENESES MORALES, Ernesto et al. Tendencias educativas oficiales en México 18211911. México: Ed. Porrúa, 1993, p. 75.

${ }^{47}$ Se trata del decreto XXXV que consta de 19 artículos detallando la instalación y funciones del nuevo plantel, GRANJA, Eliseo J. (comp.). Colección de leyes, decretos, reglamentos y disposiciones sobre instrucción pública por el Gobierno del Estado desde el año de 1824 a la fecha. Oaxaca: Impr. del estado, 2 tomos, 1894, t. I, p. 2.

${ }^{48}$ GRANJA, Eliseo J. (comp.). Colección de leyes, decretos, reglamentos y disposiciones sobre instrucción pública por el Gobierno del Estado desde el año de 1824 a la fecha. Oaxaca: Impr. del estado, 2 tomos, 1894, t. I, p. 2.
} 
Ese mismo año se estableció una suscripción para costear una escuela de enseñanza mutua en la importante población de Miahuatlán, cabecera del departamento del mismo nombre, al sur de los Valles Centrales ${ }^{49}$. Al igual que en la ciudad de Oaxaca la enseñanza sería gratis para los niños sin recursos, pero no para aquellos cuyos padres tuvieran posibilidades, quienes deberían aportar una cooperación mensual de un peso. En ese proyecto la municipalidad tendría particular intervención ${ }^{50}$.

Según datos del escritor miahuateco Basilio Rojas, la escuela inició sus trabajos en enero de 1826 bajo la conducción de su abuelo Basilio J. Rojas, el cual contaba a la sazón con 20 años y quien luchó contra todos los obstáculos para mantener funcionando el centro escolar. Pronto "de aquella escuela empezaron a salir los preceptores para los pueblos para llevar a los indios el silabario y el catecismo, las cuatro operaciones fundamentales y los mandamientos". La primera escuela abierta merced la de Miahuatlán fue la vecina población de Santa Catarina Cuixtla ${ }^{51}$.

\section{La administración}

La ley orgánica para el gobierno de Oaxaca aprobada en mayo de 1824, en el artículo 15 instauraba que los gobernadores de los departamentos cuidarían que los ayuntamientos cumplieran sus deberes, principalmente en el establecimiento y buen orden de las escuelas de primeras letras. El cumplimiento de estos preceptos se dificultaba por el lento crecimiento de los servicios educati-

\footnotetext{
${ }^{49}$ Según información aportada por José Ma. Murguía y Galardi en 1818, el partido de Miahuatlán era el más rico de la provincia oaxaqueña debido a la abundancia de grana que se cosechaba y de su calidad y la cabecera albergaba a una población superior a las mil personas. MURGUÍA Y GALARDI, José María. Apuntamientos estadísticos de la provincia de Oaxaca en esta Nueva España. Oaxaca: Ediciones bibliográficas del Ayuntamiento de Oaxaca de Juárez, A. C./Edamex, 1991, p. 51.

${ }^{50} \mathrm{Si}$ el producto de la colecta no fuera suficiente, el gobernador de aquel departamento, a propuesta de la municipalidad miahuateca, propondría "otros arbitrios a la legislatura". En tanto, se dispondría de los fondos municipales para los gastos de la anunciada escuela, siempre y cuando no pasaran de 200 pesos anuales. Cf. Colección de leyes, decretos y circulares del Estado de Oaxaca, 1898, (2a. edición). Oaxaca: Imprenta del Estado, t. I, apéndice, p. 47-48.

${ }^{51}$ Cf. ROJAS, Basilio. Miahuatlán, un pueblo de México. México, dos tomos, 1962, t. II, p. 85-87. La obra educativa de Rojas se extendió hasta bien entrado el siglo XIX cuando falleció. Su nombre seguirá apareciendo en estas páginas. No se sabe con certeza si el entusiasta promotor de la educación y también del cultivo del café egresó de la escuela de Manuel T. Orozco.
} 
vos; un viajero alemán residente en la capital oaxaqueña en la década de los treinta anotaba que el sistema escolar citadino dejaba mucho que desear. En la ciudad de Oaxaca reportaba la existencia de siete escuelas públicas elementales, de las que cinco - entre ellas una de niñas y la lancasteriana - vivían gracias a los fondos municipales, otra estaba financiada por los religiosos betlemitas y una más por la beneficencia privada. También existían varias escuelas particulares para niños y niñas ${ }^{52}$. Fuera de la capital - escribía Mühlenpfordt - las cosas no eran mejores, de 921 poblaciones existentes sólo en 395 había escuelas elementales, "la mayoría miserables en extremo"; de ellas, cuatro eran sostenidas por fundaciones de beneficencia mientras que la inmensa mayoría dependía de los ayuntamientos o de "aportaciones voluntarias de la población" 53 .

El gobernador López Ortigoza en su informe de 1832 señalaba que habían muchos pendientes en el terreno educativo, pues si bien el número de escuelas había crecido, Jamiltepec, Zaachila y otras poblaciones carecían de escuelas, no obstante haber contado con ellas en el pasado ${ }^{54}$.

Otro testimonio, en este caso del prefecto del departamento de Villa Alta en 1837, ilustra la situación en la Sierra Norte, donde existían 83 escuelas de primeras letras y asistían cerca de 5 mil educandos, pero deficientes, pues solamente se enseñaba a "cantar en tonos desagradables la doctrina del Padre Ripalda y a leer la cartilla". Por lo general los preceptores eran nativos de ahí mismo, escogidos entre los "que se creen más aptos o porque han estado al servicio de algún párroco o porque en la capital aprendieron algunas expresiones castellanas" 55 .

Para este funcionario, la falta de "propios y arbitrios" impedía la búsqueda de personas competentes para la enseñanza de los niños, porque, a su decir, la dotación anual de los preceptores era de 35 o 40 pesos anuales, junto con unos cuantos almudes de maíz, de chile y de sal, o bien se les exceptuaba de los

\footnotetext{
${ }^{52}$ MÜHLENPFORDT, Eduardo. Ensayo de una descripción fiel de la república de Méjico, con especial referencia a su geografía, etnografía y estadística. El Estado de Oaxaca. México: Codex-Tule, 1993, p. 14.

${ }^{53}$ MÜHLENPFORDT, Eduardo. Op. Cit., p. 14.

${ }^{54}$ Memoria administrativa, 1832, p. 20.

${ }^{55}$ Diario del Gobierno de la República Mexicana, 1843.
} 
tequios. Con tales perspectivas, quién "convendría en abandonar su país para vivir en estos pueblos llenos de hambre y de miseria" 56 .

Como vimos, las minorías ilustradas locales insistían en la conveniencia de que el gobierno fomentara y protegiera la educación. Uno de sus exponentes, Juan B. Carriedo, escribía en las páginas del periódico local El Zapoteco que el interés general exigía leyes sabias que removieran los obstáculos de "la circulación de las luces" ${ }^{\circ 7}$.

El mismo Carriedo, en su Ensayo histórico estadístico del Departamento de Oaxaca (1843), escribió que debían desecharse los métodos antiguos de enseñanza primaria, pagársele a los preceptores estipendios razonables, aumentar el número de escuelas de los distritos y procurar que los maestros tuvieran las cualidades indispensables para cargo tan delicado y evitar individuos ignorantes y de conducta viciosa que corrompieran a la juventud en vez de educarla ${ }^{58}$.

No obstante, la penuria de los fondos públicos se manifestó en cada momento. Lo evidencia la petición que hace el alcalde primero del ayuntamiento oaxaqueño y protector de escuelas en 1824, doctor Juan Nepomuceno Bolaños, a los prelados de los conventos de San Agustín, Santo Domingo, San Francisco y La Merced a fin de que proporcionaran un espacio en sus claustros para instalar sendas escuelas pías de primeras letras ${ }^{59}$.

Con todas esas dificultades, a mediados de los cuarenta, el profesor del Colegio Comercial e impresor Juan B. Carriedo comentaba que las escuelas sostenidas por el ayuntamiento oaxaqueño eran cinco, de las cuales una era para niñas, con un matrícula de 1067 alumnos, a esa cantidad se sumaban 207

\footnotetext{
${ }^{56}$ Diario del Gobierno de la República Mexicana, 1843. Pando proponía que los pueblos destinaran los productos de una siembra del común para hacerse de fondos a utilizarse para el pago de buenos preceptores; otra fuente sería gravar a las tepacherías con cuatro o seis reales mensuales. A ese fondo habría que sumarle lo que los pueblos destinaban a sus preceptores, de manera que calculaba que se haría una cantidad con la que pudieran establecerse buenas escuelas al menos en las cabeceras de parroquia a donde podrían acudir los niños de los lugares inmediatos.

${ }^{57}$ El Zapoteco, 1833, p. 3,4. Este periódico era el órgano de expresión de los federalistas locales, conocidos en el argot provinciano como "vinagres".

${ }^{58}$ CARRIEDO, Juan B. Ensayo histórico estadístico del departamento de Oaxaca. Oaxaca: Impr. del Estado, 1889.

${ }^{59}$ El Regenerador. Oaxaca, t. VII, 1842, p. 4. Solamente el de San Agustín dio una respuesta categóricamente afirmativa.
} 
escolares provenientes de los colegios establecidos en los conventos del Carmen y San Agustín y el sostenido por el Estanco y otros 300 que calculaba estudiaban en establecimientos particulares. El mismo autor calculaba en 20 mil los inscritos en escuelas diseminadas en la entidad ${ }^{60}$.

Benito Juárez llegó al poder en Oaxaca cuando aún estaban en territorio mexicano las tropas norteamericanas, pero pasadas las secuelas del conflicto bélico se dedicó a instrumentar algunos proyectos para el desarrollo de la entidad. En su primer informe de gobierno el mandatario notificó abiertas 476 escuelas de primeras letras en el estado, localizándose el mayor número en el departamento de Teposcolula, en la región de la Mixteca, seguido del serrano de Villa Alta con 112 establecimientos sostenidos por los pueblos ${ }^{61}$.

A pesar de esa cifra, Juárez destacaba que no era el número que requería la entidad a su cargo, ni tampoco los preceptores existentes los más idóneos para "educación sólida y filosófica" de la niñez, toda vez que las municipalidades no contaban con fondos suficientes; mas el problema de fondo radicaba en lo que denominaba "la miseria pública" que impedía a los infantes acudir a los centros escolares, pues sus padres consideraban a la instrucción como un bien remoto ${ }^{62}$.

Como político práctico, Juárez sabía que las soluciones basadas en la mera teoría no eran sino especulación; así, en los informes subsecuentes se encuentran medidas concretas para mejorar el estado de las fondos municipales destinados a la educación y, en casos particulares como en la escuela de enseñanza mutua establecida en Zaachila, la intervención del gobierno para la compra de útiles y la paga del docente encargado ${ }^{63}$.

\footnotetext{
${ }^{60}$ CARRIEDO, Juan B. Estudios históricos y estadísticos del Estado oaxaqueño. México: Talleres de Adrián Morales S., Biblioteca de autores y de asuntos oaxaqueños, dos tomos, 1949 , t. II, p. 172-175.

${ }^{61}$ TAMAYO, Jorge L. (ed.). Benito Juárez. Documentos, discursos y correspondencia. México: Sepanal, 1964, p. 561.

${ }^{62}$ TAMAYO, Jorge L. (ed.). Benito Juárez. Documentos, discursos y correspondencia. México: Sepanal, p. 562. Convencido de las bondades del credo liberal el mandatario manifestaba que esas trabas podrían conjurarse con facilitando el libre tránsito de las mercancías abriendo vías de comunicación terrestres y marítimas que permitieran que los frutos de la agricultura y el comercio locales se realizaran fuera de las fronteras del estado y entonces los padres de familia, "sin excitación ni prevención de la autoridad pública, dotarán escuelas, fundarán establecimientos literarios y los lllenarán de sus hijos, cooperando de una manera eficaz al desarrollo de la inteligencia, sin que la que los pueblos serán siempre miserables y degradado”.(p. 563)
}

${ }^{63}$ TAMAYO, Jorge L. (ed.). Op.Cit., p. 682. 
En la siguiente década, el movimiento de Reforma se inició con fuerza y se expidió la nueva constitución federal en febrero de 1857. Siguió en Oaxaca, como en el resto de la república, la elaboración de cartas constitucionales. En la Constitución local brevemente se reafirmaba el deber de los ayuntamientos para "administrar la instrucción primaria" "64, mientras que la Ley orgánica para el gobierno del estado, publicada el mismo año, les atribuía la facultad de: "establecer escuelas de primeras letras porque los niños de ambos sexos concurran diariamente, para lo que el presidente del ayuntamiento podrá imponer a los padres de familia culpables (de la inasistencia) alguna correccional..." ${ }^{\prime 65}$. Finalmente, la Ley de instrucción pública de 1860 reiteraba la responsabilidad de las autoridades municipales para con la creación y vigilancia de las escuelas de sus pueblos ${ }^{66}$.

Ahora bien, en el reglamento para las escuelas municipales de primeras letras aprobado por la Dirección de Instrucción Pública en 1861, a los municipios correspondía la vigilancia de la asistencia constante y el desempeño de los preceptores, así como el control de la concurrencia de los niños a los salones de clase ${ }^{67}$. Años más tarde, en un nuevo reglamento, los presidentes y agentes municipales adquirían la facultad de cobrar una multa a los padres de familia que no mandasen a sus hijos a la escuela, misma que se sumaría a los demás fondos para la educación en los pueblos.

Con relación al tema del financiamiento, a pesar de la Ley de desamortización, los ayuntamientos parecen haber mantenido unos fondos, "fincas o capital", destinados a sostener la educación primaria ${ }^{68}$. Se establecía por primera vez que la enseñanza primaria elemental era gratuita y obligatoria y podrían asistir niños de ambos sexos. Su duración era de dos años y comprendería las materias dictadas por la Dirección de instrucción pública.

\footnotetext{
${ }^{64}$ SÁNCHEZ SILVA, Carlos y RUIZ CERVANTES, Francisco José. Las constituciones políticas de Oaxaca. Oaxaca: Gobierno del Estado, Cámara de Diputados, UABJO, p. 169. ${ }^{65}$ Ley Orgánica, 1857.

${ }^{66}$ RUIZ CERVANTES, Francisco José. La educación oaxaqueña en sus leyes.. Oaxaca: IEEPO, Colección "Voces del fondo", 2001, p. 29.

${ }^{67}$ Colección de leyes, decretos y circulares del Estado de Oaxaca, t. IV (2a. edición). Oaxaca: Imprenta del Estado, 1898, p. 210-211.

${ }^{68}$ Colección de leyes, decretos y circulares del Estado de Oaxaca, t. IV (2a. edición). Oaxaca: Imprenta del Estado, 1898, p. 279 (Reglamento de 1867.)
} 
Dos años más tarde, en su calidad de titular de la Dirección de instrucción pública, el abogado Manuel Dublán redactó un valioso informe sobre los trabajos realizados durante su gestión: Memoria que sobre instrucción pública presenta el director del Instituto al gobierno del Estado. En el documento, el también director del Instituto de Ciencias y Artes informaba que según datos de 1862 un total de 21 mil alumnos concurrían a las escuelas diseminadas en el estado de Oaxaca. En relación a la población total entre 8 y 18 años, la población escolar se calculaba en alrededor del $25 \%$. Sin embargo, esta situación no era la ideal, ni los métodos, ni los profesores, ni los resultados de la educación podían dejar satisfechos a nadie, pues escribía: “ ¿qué importa que haya muchos establecimientos y que estén muy concurridos, si la juventud no aprende nada de provecho?”.

El diagnóstico era severo:

"con excepción de las de la capital y las de algunas cabeceras de Distrito, las demás escuelas son de muy poca utilidad. Apenas se enseña a leer mal, a escribir peor y el catecismo de Ripalda. Escuelas hay en el Estado, en que no se aprende ni aun eso, sino que la educación se reduce al rezo o canto y esto en zapoteco, mixteco o chinanteco, de la doctrina cristiana, que entona algún habitante del lugar, ${ }^{, 70}$.

Qué podría hacerse, - se preguntaba el liberal moderado - si los sueldos de los profesores oscilaban entre dos y diez pesos mensuales e incluso había comunidades donde pagaban menos de un peso. Escéptico, señalaba que todas las quejas sobre el poco adelanto en las escuelas, atribuido a la incapacidad de los preceptores y a los magros fondos para retribuir sus esfuerzos, eran razonables; mientras no mejoraran los métodos de enseñanza, se imprimieran libros

\footnotetext{
${ }^{69}$ Memoria que sobre instrucción pública presenta el director del Instituto al gobierno del Estado, Oaxaca, 1863, p.37 Una de las razones para que el ICAEO tuviera sus talleres era que produjera material impreso para las escuelas del estado. Cf. RUIZ CERVANTES, Francisco José. "Algunas notas sobre la enseñanza de la tipografía en Oaxaca" en Acervos. Oaxaca, vol. 3, abril-septiembre, 1999, pp. 41-44.

${ }^{70}$ Memoria que sobre instrucción pública presenta el director del Instituto al gobierno del Estado, Oaxaca, 1863, pp. 11-12.
} 
elementales en número conveniente y se pagara regularmente a los profesores no se obtendrían resultados positivos ${ }^{71}$.

Pero ello sería inutil si no se reformaba radicalmente el sistema, la enseñanza gratuita encomendada a las municipalidades tenía un obstáculo poderoso: la miseria en que se debatían los pueblos ${ }^{72}$. Así, el sistema municipal de “enseñanza gratuita" no podía dar resultados a menos que variaran las condiciones de las comunidades ${ }^{73}$.

Para Dublán la penuria de los pueblos hacía ineficaces los esfuerzos de la administración pública y volvía inaplicable que la educación recayera sobre los municipios, proponía la creación de un Liceo en cada cabecera de distrito. El profesor encargado sería nombrado y pagado por la Dirección de instrucción pública, es decir, por el gobierno del estado, que fijaría los métodos y proveería los libros elementales necesarios.

Para atraer aspirantes se anunciaba la admisión de todos los jóvenes del distrito que lo requirieran; pero sería obligatorio para cada pueblo, hacienda o rancho enviar uno, dos o más niños según sus recursos. La manutención de estos alumnos correría a cuenta del respectivo municipio, siempre que, a juicio de la autoridad, el padre no pudiera costearla.

Dublán proponía se establecieran en esos "liceos" bibliotecas para adultos con "periódicos, libros elementales de agricultura, arte y oficios, economía doméstica, ganadería y nociones de moral"74.

Con relación a la formación de profesores, Dublán consideraba apremiante el restablecimiento de la escuela central tal como se abrió en 1862, pues la institución había representado un modelo pedagógico: "si se quieren tener para el porvenir profesores instruidos que generalicen una enseñanza sólida" 75 .

\footnotetext{
${ }^{71}$ Los jefes políticos mensualmente elaboraban un reporte para el gobierno del Estado sobre diversos aspectos de administración pública, que por lo general se publicaban en La Victoria. De esos breves informes Dublan documentaba lo asentado en el informe glosado aquí. Por ejemplo, de Villa Alta, la autoridad política reportaba que en abril de 1863, algunas escuelas estaban cerradas porque las siembras habían empezado y "por una costumbre antiquísima, los padres de familia mandan a sus hijos a cuidar sus milpas y ganado" La Victoria, t. IV, n. 2, 9 de julio de 1863, p. 1. ${ }^{72}$ En el mes de junio de ese año, según el Jefe político de Coixtlahuaca, las escuelas de Tepenene, Nativitas, Otla y San Cristobal Suchixtlahuaca cerraron por la penuria de los ciudadanos que ya no podían pagar a los preceptores. La Victoria, Oaxaca, t. IV, n. 13, 16 de agosto de 1863, p.1.

${ }^{73}$ La Victoria, Oaxaca, t. IV, n. 13, 16 de agosto de 1863, p. 13.

${ }^{74}$ La Victoria, Oaxaca, t. IV, n. 13, 16 de agosto de 1863, p. 13-14.

${ }^{75}$ La Victoria, Oaxaca, t. IV, n. 13, 16 de agosto de 1863, p. 14.
} 
En el documento citado, Dublán proponía la creación de otros colegios de enseñanzas especializadas, minas y ciencias físicas, agricultura, artes y oficios, bellas artes y uno más destinado a la educación de la mujer, toda vez que la sociedad la había desatendida como género. Un colegio donde se enseñaran no únicamente prácticas devotas que debilitan el sentimiento religioso y fomentaban la gazmoñería, sino

"lectura, escritura, elementos de aritmética, dibujo, nociones de geografía,
de urbanidad, de moral, de economía doméstica, y las habilidades propias
del sexo, como el bordado en sus diversos ramos, el tejido de gancho, el
canto, el arte de la cocina y demás labores propias de la mujer". ${ }^{76}$

Sin embargo, los tiempos seguían siendo poco propicios para los asuntos educativos. Menos de un año de emitido la muliticitada Memoria, Oaxaca sería una entidad sitiada por el ejército invasor francés y en 1865 caería en poder de las fuerzas del Imperio de Maximiliano.

Concluido el sitio militar las cosas comenzaron a normalizarse, poco a poco las escuelas fueron reabiertas bajo la dirección del regidor de instrucción; uno de ellos, José María Castro, procuró la elaboración de muebles nuevos, las proveyó de materiales escolares y sujetó a todas al método de Lancaster ${ }^{77}$.

Y hablando de ella, considerada la escuela número uno, volvió a quedar bajo la dirección de Manuel T. Orozco, iniciador de la enseñanza mutua en la región y uno los oaxaqueños simpatizantes de la administración imperial que sustituyó al régimen republicano y, sin duda, un hombre de edad más que madura. Según la información de un acta del examen ocurrido en el otoño de 1865 tenemos que en la mencionada escuela lancasteriana existían una clase de escritura, otra de lectura, una más de "buena sociedad", además de gramática y aritmética ${ }^{78}$.

De acuerdo a los datos proporcionados por el tesorero municipal, en la ciudad capital, en 1866 existían cinco escuelas municipales, una de ellas de mujeres y

\footnotetext{
${ }^{76}$ Dublán incorporaba para las "manualidades" parte del plan de estudios del colegio particular para niñas establecida, por la maestra María Blasa de Cerviño, en los años cuarenta. El Regenerador, Oaxaca, t. VII, n. 35, 2 de mayo de 1842. La propuesta de Dublán sería parcialmente retomada años después por el chinaco Porfirio Díaz, recién tomada la ciudad de Oaxaca a finales de 1866.

${ }^{77}$ La Paz, t. I, n. 31, 6 de mayo de 1866, p. 4.

${ }^{78}$ El Boletín oficia, Oaxaca, t. I, n. 85, 24 de diciembre de 1865, p. 1.
} 
la matrícula total era 749 alumnos, entre hombres y mujeres. En tanto, funcionaban seis escuelas particulares, la mitad era de varones y la otra de niñas ${ }^{79}$.

Nuevamente aparecieron en las páginas del Boletin oficial anuncios de profesores que brindaban sus servicios. Uno de ellos, de nombre Guillermo Jansen presentaba su lista de materias: lectura, escritura, gramática castellana, aritmética, las mismas de la Lancasteriana pero se agregaban geografía y francés ${ }^{80}$. Otro, de origen italiano, Carlos Natucci, ofrecía lecciones de lengua y literatura italiana, latín para los niños y geografía e historia de Europa (antigua y Edad Media) ${ }^{81}$.

Como se ve, hubo algunas novedades en el año y meses que duró la administración imperial en la capital oaxaqueña, aunque en el interior no sabemos, el trabajo impuesto con antelación por Basilio Rojas en Miahuatlán seguía en acción, favorecido por el nombramiento del activo ciudadano como subprefecto. No deja de llamar la atención que Manuel Dublán, redactor del informe del 63 y colaborador del nuevo régimen, al frente de sus cargos en el ramo educativo, no hubiera insistido en sus antiguas propuestas, tal vez porque se trasladó a la ciudad de México ${ }^{82}$.

Habría que esperar a quienes encabezados por el guerrillero Porfirio Díaz andaban dando golpes audaces en la Costa y la Mixteca a las fuerzas imperiales. Hacia noviembre de 1866, después de una serie de victorias militares, el rebelde oaxaqueño había recuperado la capital del estado. Se encargó de reorganizar la administración pública, derogar impuestos, nombrar nuevo director del Instituto de Ciencias y Artes y, en uso de sus facultades extraordinarias en los órdenes militar y político, decretaba el establecimiento en Oaxaca de la llamada Academia de Niñas, que estaría bajo la vigilancia del Instituto y la protección del Gobierno del Estado ${ }^{83}$.

\footnotetext{
${ }^{79}$ La Paz, Oaxaca, t. I, n. 28, 31, 15 de abril y 6 de mayo de 1866, p. 4.

${ }^{80}$ La Paz, Oaxaca, t. II, n. 52, 2 de septiembre de 1866, p. 4.

${ }^{81}$ La Paz, Oaxaca, t. II, n. 53, 9 de septiembre de 1866, p. 4.

${ }^{82}$ La Paz, Oaxaca, 24 de diciembre de 1865, p. 2,3.

${ }^{83}$ Colección de leyes, decretos y circulares del Estado de Oaxaca, 1898, t. IV (2a. edición), p. $170-172$.
} 


\section{La formación docente}

La Constitución política oaxaqueña expedida en 1825 implntó ambiciosamente que en todos los pueblos del estado deberían abrirse escuelas de primeras letras, en donde se enseñaría a leer, escribir y contar, el catecismo de la religión católica y otro catecismo político en donde se expondrían "los derechos y obligaciones civiles y políticas y de las leyes penales" ${ }^{\text {" }}$. Para estar en consonancia con ese postulado, en la ley de instrucción pública promulgada al año siguiente se decía claramente que todo oaxaqueño que se considerara capaz de enseñar alguna ciencia política, natural o eclesiástica, nobles artes o idiomas sería libre para hacerlo, previo conocimiento de la autoridad política del lugar en que residiera ${ }^{85}$.

Los preceptores serían inscritos en un libro y serían considerados "profesores públicos" una vez que presentaran "uno o más jóvenes suficientemente aprovechados en la facultad que les enseñaren". A estos docentes se les prometía extenderles el diploma respectivo y gozar de los honores y privilegios de los catedráticos del Colegio Seminario ${ }^{86}$.

Con tales prebendas los legisladores oaxaqueños buscaban animar al mayor número de ciudadanos para ejercer el oficio de docencia y no estar atados únicamente a los resultados iniciales de la escuela lancasteriana establecida en la capital oaxaqueña ${ }^{87}$.

Varias de aquellas disposiciones fueron suprimidas en 1835, no obstante las restricciones impuestas al estatuto magisterial particular en la legislación educativa, en la capital oaxaqueña se abrieron nuevos colegios. Esto se sustenta en los avisos de la prensa local destinados principalmente a la elite local que

\footnotetext{
${ }^{84}$ RUIZ CERVANTES, Francisco José (coord.). Un siglo de legislación educativa en Oaxaca. Oaxaca: Casa de la Cultura Oaxaqueña, col. "Agua quemada”, 1987, p. 46.

${ }^{85}$ RUIZ CERVANTES, Francisco José (coord.). Op. Cit., . 47.

${ }^{86}$ RUIZ CERVANTES, Francisco José (coord.). Op. Cit. .

${ }^{87}$ En 1835 , el privilegio acordado en el artículo quinto de la ley de instrucción pública es derogado y la vigencia de los cuatro primeros artículos relativos a las facilidades para instalar escuelas, escoger métodos de estudio, estipendios, etcétera quedan circunscritos fuera de la capital de Oaxaca. GRANJA, Eliseo J. (comp.). Colección de leyes, decretos, reglamentos y disposiciones sobre instrucción pública por el Gobierno del Estado desde el año de 1824 a la fecha. Oaxaca: Impr. del estado, 2 tomos, tomo 1, 1894, p. 29.
} 
quisiera ocupar sus servicios para la educación de sus hijos. En esa etapa iniciará sus labores el célebre maestro Juan de Esesarte ${ }^{88}$.

Como ya hemos señalado, en la siguiente década Benito Juárez se dedicó a implementar medidas concretas para mejorar el sistema educativo estatal. En relación con quienes enseñaban, su gobierno dio pasos para formar docentes mejor preparados y con ese motivo expidió un decreto (19 de agosto de 1850), por el cual deberían establecerse "escuelas normales" en las cabeceras de todos los departamentos y partidos del estado ${ }^{89}$.

Los alumnos y futuros maestros debían ser jóvenes entre quince y veinte años, "hábiles y capaces de recibir instrucción competente" los cuales saldrían a razón de uno por pueblo. La manutención debía correr por cuenta de sus padres, pero en caso de extrema pobreza por "el común del pueblo" de donde provinieran. El programa de estudios consistía en lo mismo que los anteriores programas. Los preceptores encargados de instruir a los futuros docentes recibirían su sueldo de las cooperaciones entregadas por los pueblos a razón de un peso mensual ${ }^{90}$.

Los egresados de las normales deberían encargarse de la educación primaria de la juventud de sus pueblos, durarían en su encargo el tiempo necesario para que instruyeran, por lo menos, a seis jóvenes "con toda la perfección posible". Los citados preceptores de primeras letras disfrutarían de un sueldo que el ayuntamiento, de acuerdo con el gobernador o subprefecto, les designaren ${ }^{91}$.

Según los informes de la época pudieron abrirse dichos establecimientos en Nochixtlán, Choapan, Zoochila, Ixtlán, Ocotlán, Yautepec y Jamiltepec. En algunos de ellos los docentes encargados habían egresado de la Normal lancasteriana establecida en Oaxaca ${ }^{92}$.

\footnotetext{
${ }^{88}$ Para la ciudad de México y durante la Reforma y el Imperio de Maximiliano véase el artículo de Bermudez, María Teresa, "La docencia en oferta: anuncios periodísticos y escuelas particulares, 1857-1867" en Historia Mexicana. México, vol XXXIII, n. 131, enero-marzo 1984, pp.214-253.

${ }^{89}$ Colección de leyes, decretos y circulares del Estado de Oaxaca, t. IV (2a. edición). Oaxaca: Imprenta del Estado, 1898, t. I, pp. 683-85.

${ }^{90}$ Colección de leyes, decretos y circulares del Estado de Oaxaca, t. IV (2a. edición). Oaxaca: Imprenta del Estado, 1898, t. I, p. 683.

${ }^{91}$ Colección de leyes, decretos y circulares del Estado de Oaxaca, t. IV (2a. edición). Oaxaca: Imprenta del Estado, 1898, t. I, p. 685.

${ }^{92}$ Eso se deduce pues en la recopilación documental preparada a fines de siglo por el historiador Manuel Martínez Gracida, los docentes encargados de las escuelas normales agradecían las enseñanzas recibidas del señor Orozco.
} 
En el último año de la administración juarista se elaboró una estadística escolar que arrojó los siguientes resultados: ocho normales, 682 escuelas municipales, 19 "amigas" como se llamaba a los cursos particulares para niñas. La matricula total registrada era de 30 mil escolares y menos de una quinta parte correspondía a estudiantes del sexo femenino ${ }^{93}$.

En cuanto a su sostenimiento las escuelas normales se mantenían con los fondos creados por el decreto que les dio origen; las municipales eran pagadas con los fondos comunales de los pueblos y cuando éstos no alcanzaban los padres de los escolares cubría el sueldo de los preceptores; igualmente "las amigas" eran sostenidas por los padres de los educandos ${ }^{94}$.

Los ánimos educativos amainaron por la presencia, por segunda vez, de una epidemia de cólera en Oaxaca, al grado que en 1850 fue emitido otro decreto que declaraba en suspenso la puesta en marcha de las instituciones normalistas ${ }^{95}$. Los redactores de semanario local La Cucarda, lamentaban la medida, inevitable por otro lado, pues, desde su óptica, el estado de las escuelas oaxaqueñas era lamentable y agregaban: "poblaciones hay que por falta de fondos y por una aversión a ilustrarse no indemnizan a los maestros, sino con cuatro u ocho pesos mensuales que las más de las veces no les pagan". En esas condiciones, continuaban: “¿qué hombres de capacidad, de honradez e instrucción puede encargarse de tales planteles de enseñanza, bajo unas condiciones tan miserables y ruinosas?". Ninguno -agregaban-, por lo tanto, la única salida era el cumplimiento de la ley que se había mandado suspender ${ }^{96}$.

En 1852, en el último informe de su gobierno, Juárez ponderó la importancia del proyecto iniciado, en particular los logros obtenidos en el departamento de Villa Alta, único en el estado que tenía completo el número de estos establecimientos, en tanto en la ciudad de Oaxaca -comentaba- era notable la

\footnotetext{
${ }_{93}^{93}$ Colección de leyes, decretos y circulares del Estado de Oaxaca, t. IV (2a. edición). Oaxaca: Imprenta del Estado, 1898, t. I.

${ }^{94}$ Colección de leyes, decretos y circulares del Estado de Oaxaca, t. IV (2a. edición). Oaxaca: Imprenta del Estado, 1898, t. I.

${ }^{95}$ MÁRQUEZ, Lourdes y REINA, Leticia. "El cólera en Oaxaca en el siglo XIX" en Cuadernos del Sur. Oaxaca, año I, mayo-agosto 1992, p. 85. Las autoras comentan que las poblaciones más afectadas se ubicaron en los departamentos de Teposcolula y Huajuapan. ${ }^{96}$ La Cucarda, t. I, n. 1021 de octubre de 1850, p. 2-3.
} 
falta de una escuela normal "bien dotada, mejor surtida y desempeñada por un diestro e instruido preceptor" 97 .

Concluida la gestión juarista asumió el cargo gubernativo Ignacio Mejía, de igual filiación política, aunque su administración fue corta, debido al triunfo del Plan de Jalisco y Antonio López de Santa Anna. De tal modo en Oaxaca como en el resto del país una administración contraria en políticas y procedimientos accedió al poder y quedaron truncos los proyectos educativos ${ }^{98}$.

Durante el verano de 1860 las tropas liberales desalojaron de la ciudad de Oaxaca a las fuerzas conservadoras de Cobos poco después, el ejecutivo en su perspectiva de reorganizar la "cosa pública" daba a conocer un interesante decreto relativo a la instrucción pública elemental y a la formación de docentes.

Se creaba la creación de una escuela central normal ubicada en la ciudad de Oaxaca bajo la protección y vigilancia de la dirección de estudios, a ella deberían asistir los jóvenes propuestos por los jefes políticos, en razón de dos por distrito; su manutención correría a cargo del gobierno. Además de aquellos internos, podría haber otros con el mismo carácter pero cubriendo una pensión. Habrían también alumnos externos que se recibirían según el número de los solicitantes.

Al mismo tiempo se acordaba la clausura de las escuelas normales existentes en los distritos, los alumnos y sus implementos deberían pasar a la escuela municipal de la cabecera de distrito. Igualmente se derogaba la contribución para el sostenimiento de dichas escuelas instituida desde 1849.

En la prensa gobiernista se comentaba como bondad del nuevo proyecto, que los padres no tendrían que sustentar a sus hijos; y los municipios no contribuirían para la instrucción pública con "la desproporción que lo hacían". Así que:

"Suprimidas las escuelas normales y derogada la contribución que las sostenía, era preciso que se impusiera a los municipios el deber de sostener una escuela en la que se eduque la juventud y que se creara una escuela central en la que, sin sacrificio de parte de los pueblos, se ilustren algunos jóvenes que con el tiempo sean maestros de sus hermanos. [...]"99.

\footnotetext{
97 TAMAYO, Jorge L. (ed.). Benito Juárez. Documentos, discursos y correspondencia. México: Sepanal, 1964, t. I, p. 759. Sobre este último punto Juárez proponía que se fusionaran las escuela lancasteriana y el colegio comercial.

${ }^{98}$ El retorno a la vida civil de Juárez fue corto, pues fue nombrado titular de la recién creada Dirección de Instrucción Pública y director del Instituto de Ciencias y Artes, su gestión igualmente fue corta pues por orden superior fue expulsado de territorio oaxaqueño.

${ }^{99}$ La Victoria, Oaxaca, t. II, n. 23, 20 de octubre de 1861, p. 4.
} 
Luego de emitir el decreto de creación del colegio se dio a conocer el reglamento interior de la oficialmente denominada "Escuela Central Normal de Instrucción Primaria" ${ }^{100}$. El nuevo gobierno quería echar andar a la normal en enero de 1862, así que mientras se acondicionaba el local apropiado, se designaban a los docentes, se pedía a los jefes políticos que agilizaran los trámites para escoger a los dos jóvenes que representarían a cada uno de los distritos ${ }^{101}$.

Para su sostenimiento en el presupuesto de ese año el gobierno había programado 12 mil pesos, pero los asuntos de la guerra contra los invasores franceses absorbieron todos los dineros disponibles del erario; por esa razón, el gobierno oaxaqueño dispuso que el producto de la enajenación de un buen número de inmuebles pertenecientes a las corporaciones religiosas sirviera para los gastos del nuevo plantel ${ }^{102}$. Esta medida no fue suficiente y la escuela central normal tuvo que cerrar sus puertas y los escolares regresar a sus comunidades.

Como en el pasado, acontecimientos externos trastocaban las propuestas educativas de los liberales oaxaqueños y cancelaban la formación escolarizada de docentes tan necesarios para la ilustración de los nativos del estado sureño; habría que esperar casi dos décadas para que una nueva escuela normal de profesores abriera sus puertas.

\section{Conclusiones}

El México que entró a la vida independiente perduró, durante las siguiente cinco décadas, en la más caótica de sus etapas históricas. Conflictos internos, pérdidas de territorio, intervenciones extranjeras, desplomos económicos y rebeliones marcaron la realidad social, el pensamiento, y los intentos de crear un país proyectado hacia la modernidad.

El propósito de los ideólogos decimonónicos de transformar a los que habían sido súbditos que se identificaban en corporaciones, en una reunión de individuos-ciudadanos, políticamente concientes y activos, se enfrentó repetidamente

${ }^{100}$ GRANJA, Eliseo J. (comp.). Colección de leyes, decretos, reglamentos y disposiciones sobre instrucción pública por el Gobierno del Estado desde el año de 1824 a la fecha. Oaxaca: Impr. del estado, 2 tomos, 1894, t. I, p. 217-229.

${ }^{101}$ GRANJA, Eliseo J. (comp).Op. Cit., p. 215.

${ }^{102}$ En las páginas de La Victoria de 1862 y 1863 pueden verse avisos de la Tesorería de la Dirección de Instrucción pública del Estado anunciando remates en almoneda pública de casas en la ciudad capital. Un ejemplo, la edición del 27 de septiembre de 1863, p. 4. 
con una sociedad profundamente heterogénea que no podía cancelarse simplemente con leyes y disposiciones administrativas. De acuerdo a las cifras de la época, de cada 100 habitantes, 18 eran blancos, 22 castas y 60 indios ${ }^{103}$. Estos últimos constituían la base de la pirámide social, hacían las labores más útiles y más rudas y sólo accedían a puestos menores en la administración. El problema de volver a todos "iguales" en una sociedad tan compleja era crítico. En estados como Oaxaca donde destacaba una abrumadora mayoría indígenas, esa porción de población se volvió, en el discurso de la elite, el obstáculo a superar para alcanzar la civilización y la estabilidad. Sin embargo, pronto se difundió la teoría de que el Estado era el responsable de la transformación y se creó una cierta unanimidad alrededor de la idea que al gobierno tocaba la tarea de "elevar y emancipar" a la "raza indígena". Todos aquellos que tenían acceso a la información pública, fuera política o periodística, empezaron a confiar en la homogeneización de la sociedad mediante la educación. Una educación que, en el transcurso del siglo XIX, se volvería obligatoria, gratuita y laica.

La ilustración pública se presentaba como solución a la problemática situación de una sociedad en donde la elite se veía rodeada por grupos humanos a quienes consideraba inferiores, incivilizados e inmorales. Estos conglomerados, inestimables por su fuerza de trabajo, necesitaban ser rescatados y absorbidos por el sistema, por la clase pensante y dominante que encontró en la escuela primaria el camino hacia la prosperidad de la nación y la emancipación de la miseria.

Ahora bien, los primeros pasos fueron la expedición de leyes y reglamentos escolares, donde se prescribía la fundación de establecimientos de educación básica bajo la responsabilidad de gobiernos estatales y municipales así como la formación del personal docente. La puesta en marcha de tales ideales educativos se enfrentó a una realidad adversa manifiesta en la carencia cotidiana de fondos públicos o su uso en contingencias tales como epidemias o conflictos militares. A pesar de la penuria pública hubo momentos en donde florecieron las escuelas y no faltaron personas bienintencionadas y devotas que abrieron sus casas a escolares ávidos de conocimiento. Sin embargo, fueron gotas de agua en medio del desierto.

$\overline{{ }^{103} \text { Cf. Historia general de México, 2000. México: El Colegio de México, p. } 560 .}$ 